\title{
EFFECT OF CRYOGENIC TREATMENT ON TOOL STEEL (AISI- D $)_{2}$
}

\author{
Arvind Kaushal $^{1}$, S.K. Saluja ${ }^{2}$, R.S.S. Rawat ${ }^{3}$ \\ ${ }^{1}$ Guest Lecturer, Department of Mechanical Engineering (IGEC, Sagar) \\ ${ }^{2}$ Associate Professor Department of Mechanical Engineering (IGEC, Sagar) \\ ${ }^{3}$ Assistant Professor Department of Mechanical Engineering (IGEC, Sagar)
}

\begin{abstract}
In present scenario modernization of machine tools is on prime consideration that is an optimization of desired properties in machine tool parts means alternation of properties for that previously we employed heat treatment of steel, thus we have some improved properties but does not achieved correct solution for the problem. In modern age a new technology is comes on the front line, recognize by Acronyms C.T.P. or Cryogenic treatment of steel which has been done in cooling Atmosphere below Atmospheric tem. About $-196^{\circ} \mathrm{C}$ or- $310^{\circ} \mathrm{F}$. During this temp. Range conversion of Austenite to marten site takes place. Thus we have got increased some desirable properties like reduced wear \& Tear. Increased Hardness Micro- structure improved, Stress relieving properties also improved. In this paper tool Steel AISI- $D_{2}$ is used for cryogenic treatment \& study is performed regarding Micro- structure and Hardness, after Cryogenic treatment comparison is also made with un-treated test specimen.
\end{abstract}

Keywords:-AISI- D2, Cryogenic Treatment, Phase Transformation, Hardness, Micro- Structure -***

\section{INTRODUCTION}

Tool Steel is nothing but it is a composition of iron \& carbon Atoms Carbon/value Elaborate its variety as well as properties to get improved properties Heat treatment of steel is done not fully favorable for properties improved but along various properties some of them. In beginning of 20 century a new method is evolved that is known as Cryogenic treatment process of tool steel. Some times it is also recognized as acronyms C.T.P.throughout this process tool steel specimen OR Raw Material Specimen is taken then cooling is done. Its behaviour has been changed, the the
Austenite is just converted in martensite changing the microstructure appeared . The martensite structure achieved which resists the plastic Deformation much better the Austenite Structure. Because the carbon atoms in the marten site lattic Cryogenic treatment also known as a cold or sub-zero treatment is widely used for the better performances of components [ Das et al 2010,2009 ]. The cryogenic treatment influences the core properties of Materials Cryo- Treatment of Metals is represented by given below black Diagram.

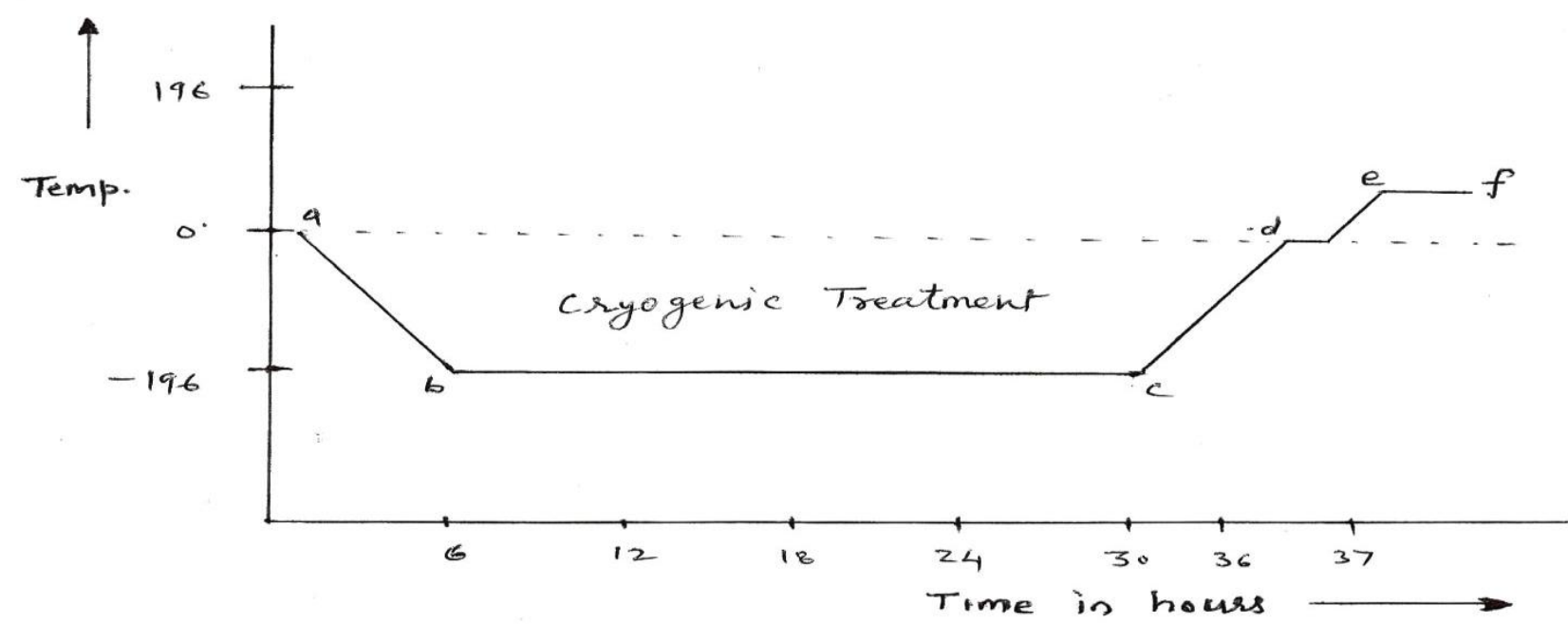

Fig 1 Cryotreatment Process

Process $(\mathrm{a}-\mathrm{b}) \rightarrow$ Cooling starts of specimen from or to $-196^{\circ} \mathrm{C}$

Process ( b- c) $\rightarrow$ Represent cooling start is content tem $\left(-196^{\circ} \mathrm{C}\right)$ for a specified time.

Process $(\mathrm{c}-\mathrm{d}) \rightarrow$ Represent regain the temp. $\mathrm{O}^{0} \mathrm{C}$

Process $(\mathrm{d}-\mathrm{e}) \rightarrow$ Heating- up to get $196^{\circ} \mathrm{C}$

Process $(\mathrm{e}-\mathrm{f}) \rightarrow$ Tempering process.

After that left for room temp, testing is taken place. 
Throughout the process phase transition achieved from austenite to marten site thus major properties of tool steel altered. By applying cryogenic treatment Dark Site of properties can be controlled which have not been in conventional heat treatment process. Due to transformation of phase of tool steel properties Altered like improved wearresistance, Hardness, toughness, fatigue resistance, microstructure of steel. It also improved resistance to the enemy of steel called stress. Cry processing is wholly applied in the field of aerospace manufacturing, sports, music instrument, also manufacturing Dies, punches, drill bits, end Mill cutter, Bearings cames, crank-shaft, block piston, blades etc.

\section{CRYOGENIC TREATMENT PROCEDURE}

\section{OR METHODOLOGY}

The liquid nitrogen as generated from the Nitrogen plant is stored in storage vessels with the help of transfer line. It is directed to a closed vaccum evacuated chamber called Cryo-
Freezer through the Nozzles the supply of liquid nitrogen into the Cryo- Freezer is operated with the help of soleniod valves. Inside the chamber gradual cooling occurs at a predefined rate/ min from the room temp of $-196^{\circ} \mathrm{C}$. Once the Sub Zero temp is reached specimen are transferred to the Nitrogen Chamber where they are stored 24 Hours with continuous supply of Liquid Nitrogen. To fulfill the required purpose AISI-D2 specimen about ( $6 \mathrm{~mm}$ Dia \& Length $45 \mathrm{~mm}$ ) whose Cryo-treatment is being performed. A Ray Diagram is very helpful to get the proper sequence and procedure.

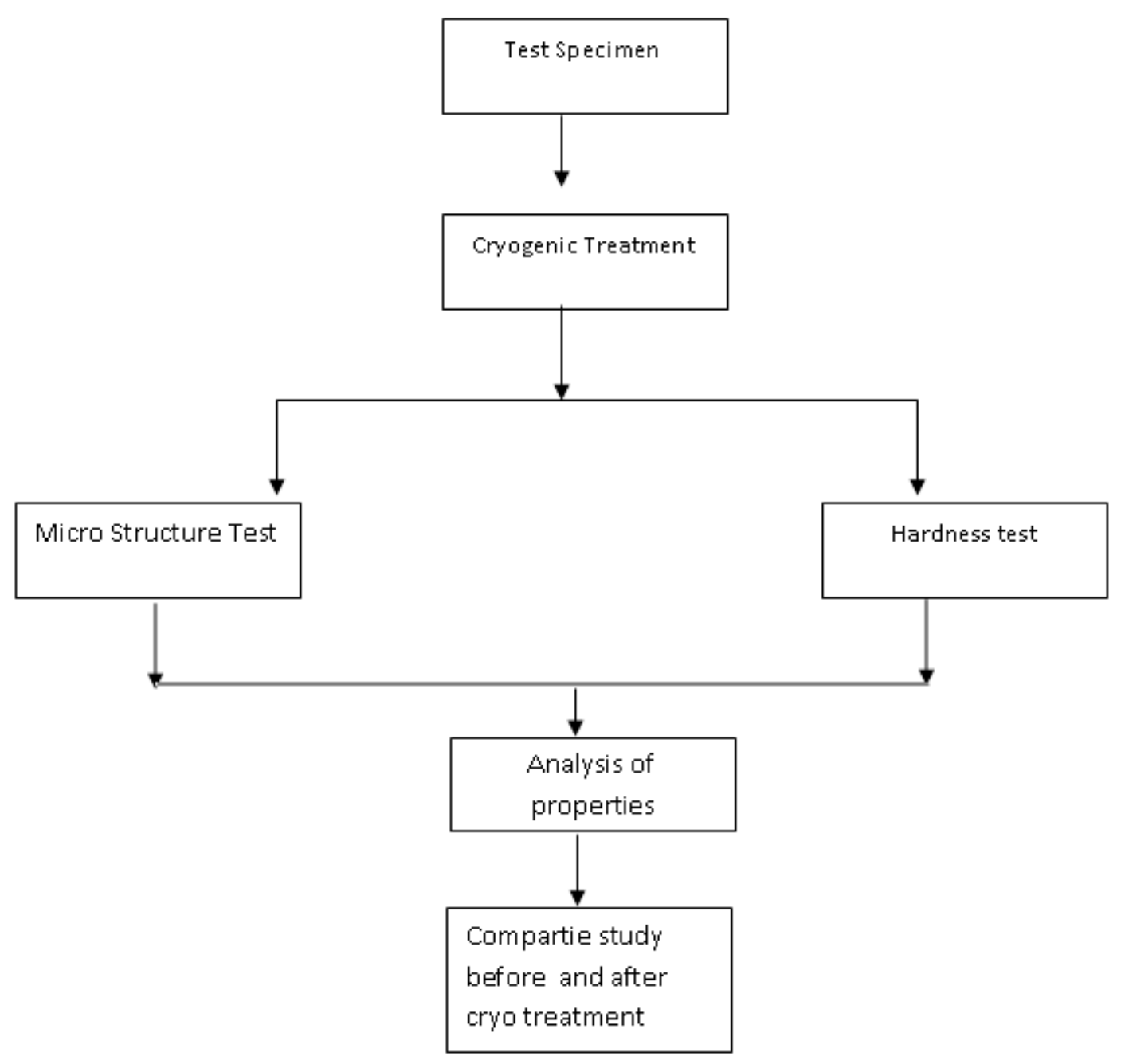

\section{RAY DIAGRAM OF PROCESS}

A block Diagram of crygenic treatment is given below in which temp maintain about $-196^{\circ} \mathrm{C}$ or $310^{\circ} \mathrm{F}$ consisting liquid nitrogen storage tank. Temperature measuring Device, cooling Device, Soleniod Value Cryo- Freezer.Inside Cryfeezere the test specimen is held up hour at $-196^{\circ} \mathrm{C}$. 


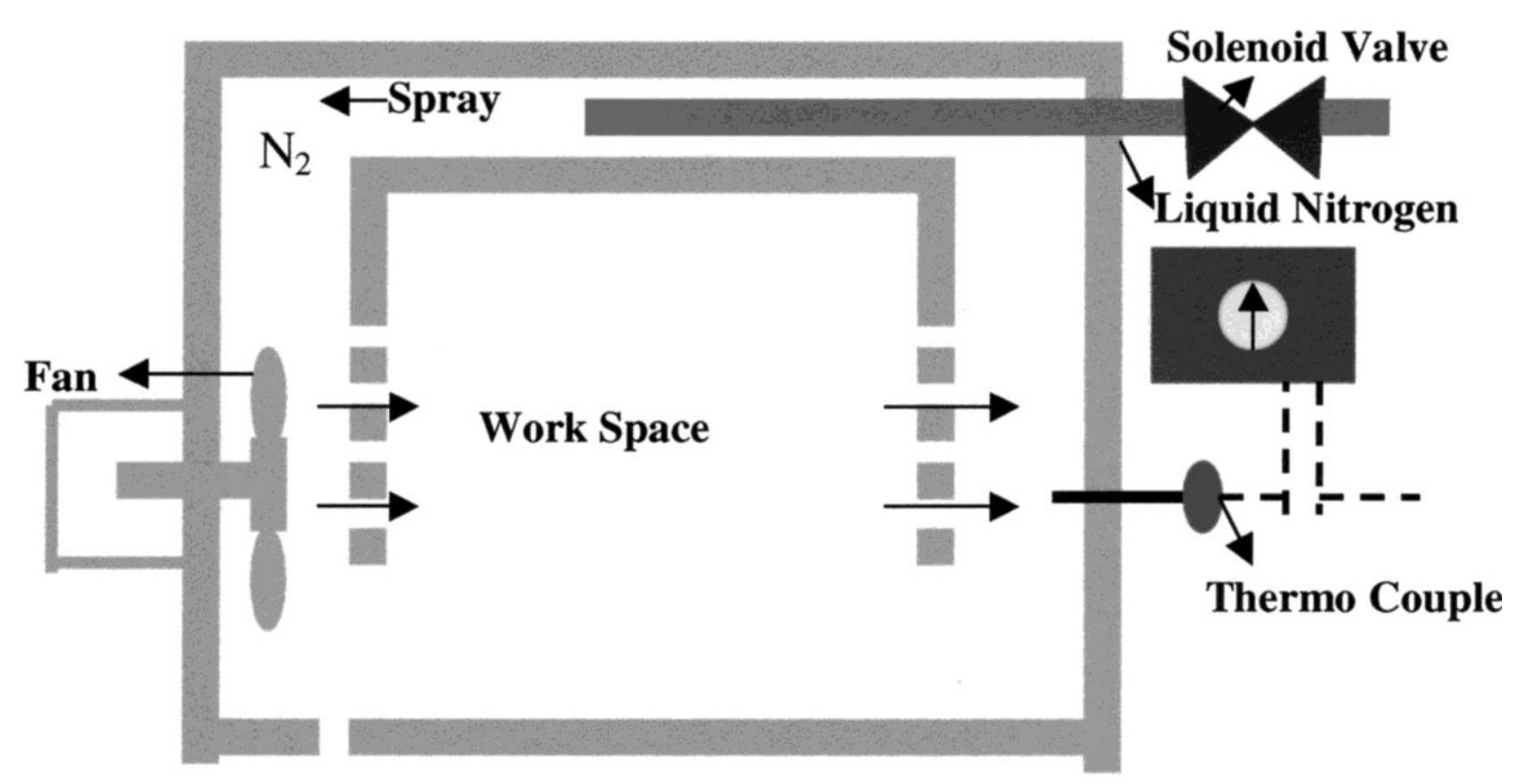

\section{Vent}

Fig 2 LIQUID NITROGEN SYSTEM ( LIQUID COOL )

\section{MICRO- STRUCTURE ANALYSES}

Micro- structure of test specimen is carried out by Optical Micro- scope for studying the behaviour of test specimen treatment and untreated both are considered.

\section{Before Cryotreatment}

Carbon in Austenite structure having poor Bonding and Bond strength.

\section{After Cryotreatment}

After Cryotretment of AISI-D2 test specimen the carbon atoms are very closed to iron atoms thus they give strong Bonding characteristics to the steel.

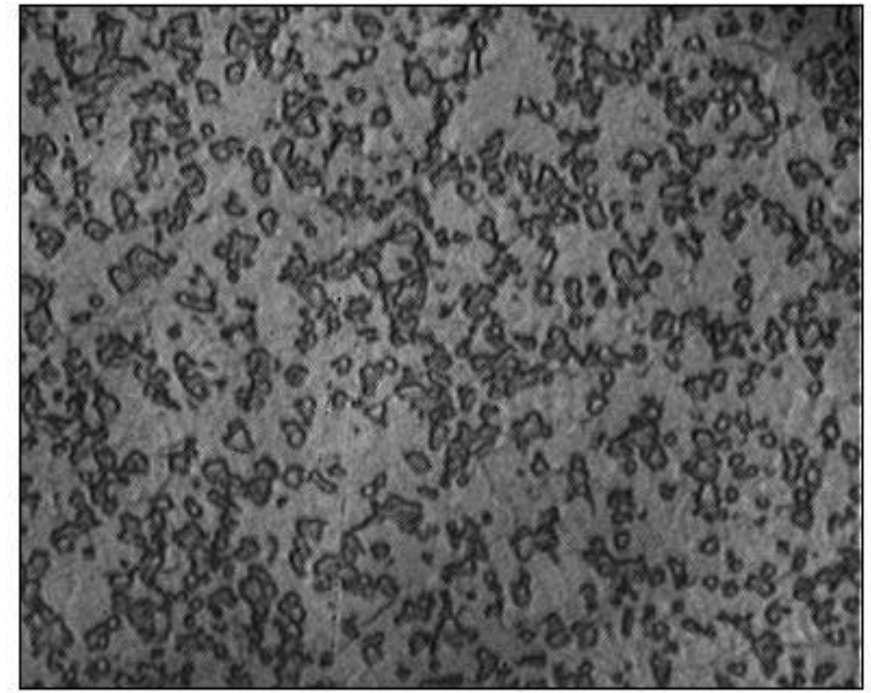

(a)

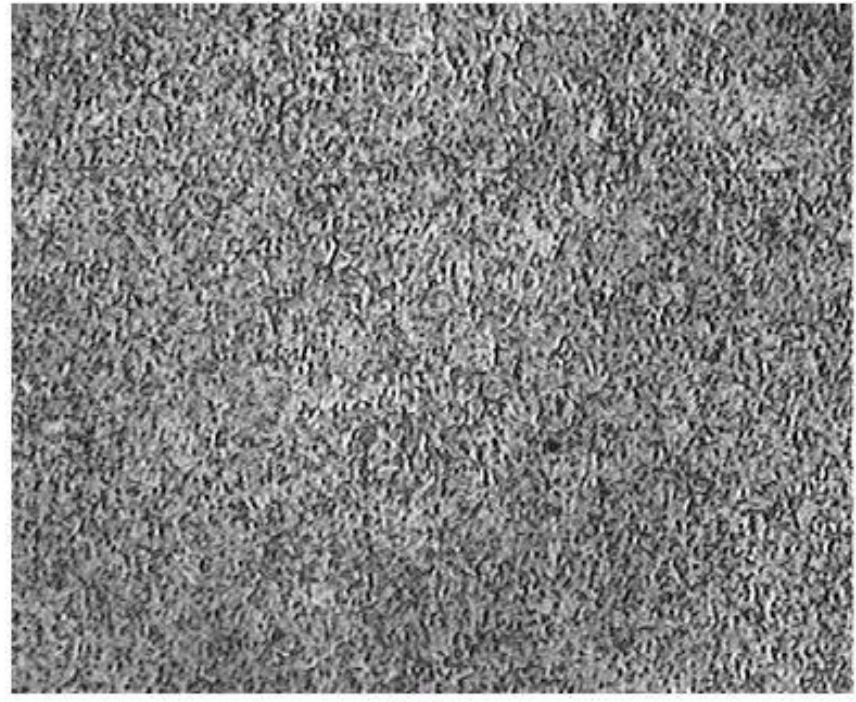

(b)

Fig 3: Micro- structure transition 


\section{HARDNESS TEST}

For hardness Testing, vickers indentation method is applied in which we observe improve hardness after Cryotreatment.

AISI-D2

Table relative performance of specimen

\begin{tabular}{|l|l|l|}
\hline S.No. & Before Cryo-treatment & After Cryo- treatment \\
\hline$(1)$ & 806 H.V. & 827 H.V. \\
\hline \multirow{3}{*}{$(2)$} & $\begin{array}{l}\text { Micro structure } \\
\text { Open- cubic structure lactice } \\
\text { (Austenite Appear ) }\end{array}$ & $\begin{array}{l}\text { closedpaked } \\
\text { Cubic structure lattice } \\
\text { (Marten site Appear ) }\end{array}$ \\
\hline
\end{tabular}

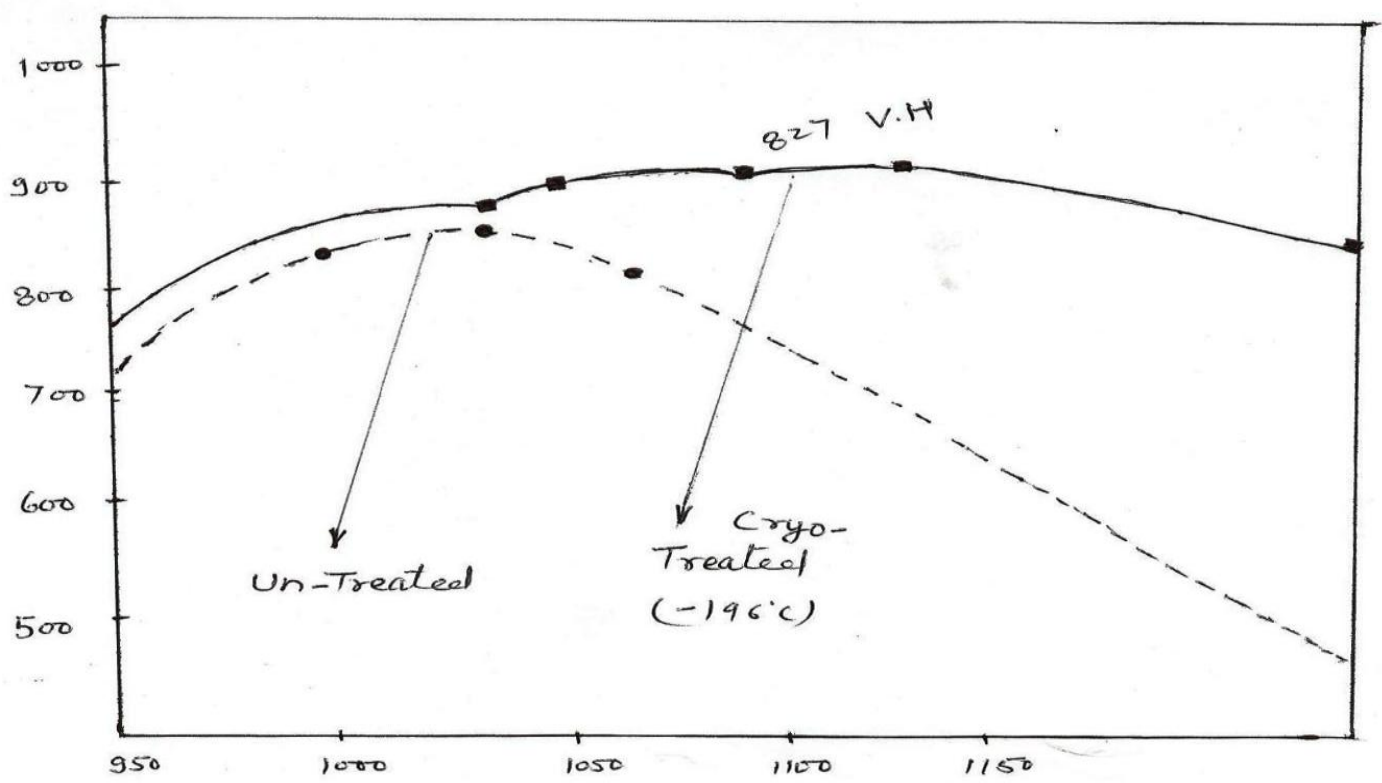

Fig 4: Relative Hardness of test specimen for treated and untreated.

If Austenitising temperature at first result in Hardness increased but at higher temperature the increasing amount of retained austenite in the structure result in an overall hardness decreases. After cryogenic treatment the peak hardness in higher and and occurs at a higher austenitising temperature .Fig 4 Shows the effect of cryogenic temp on hardness. After cryogenic treatment, the maximum hardness achieved for any given treatment occurs when all the retained Auntenite has been transformed to Martensite this normally appear between temp range $-800^{\circ} \mathrm{c}$ to á $1100^{\circ} \mathrm{C}$, If we reduced the temperature further does not increase the Hardness but slight reduction is take place.

Time is also affected the Cryogenic effects, if we increase the time then Hardness slowly increases due to martensite structure formation that has been seen in crystallographic change, and also due to increment of No.of carbide particles improvements.

\section{RESULT}

Cryogenic treatment of test specimen has been done and than hardness test is performed, the Hardness relatively with un- treated shown in graph (4) in this hardness increases after-cryogenic treatment in respect of un-treated as well as Micro- structure is also changed due to phase transition from austenite to martensite which will also altered the various properties of tool steel AISI-D2.

\section{REFERENCES}

[1] L.Bousithis G.D.Papadimtru J. Sideus, Composition of wear properties of tool steels AISI D2 and 01 with the same hardness Intobology internatinal 39,2006,pp-479-489.

[2] Collins Deep Cryogenic treatment of steels .A review, Heat Treatment of metals 1996.2 vol-23. 40-42.

[3] Hand Book of Heat Treatment of Steels by K.H. Prabudev.

[4] ASM Metal Handbook, Heat Treatment.

[5] Deep Cryogenic Treatment of a D1- Cold work tool steel 1997 page 71-74.

[6] Das D. Dutta,AK, Ray KK on 2009, 89(1) PP 55-76. 